\title{
Comparison of Molecular Properties (Stabilities, Reactivity and Interaction) of Manzamenones and Two Antimalarial Drugs (Quinine and Artemisinin) Using Mixed Method Calculations (ONIOM) and DFT (B3LYP)
}

\author{
Atse Adepo Jacques¹, Kone Soleymane1*, Diomande Sékou², Bamba El-Hadji Sawaliho1 \\ ${ }^{1}$ Laboratoire de Constitution et de Réaction de la matière de L'UFR SSMT Université Félix Houphouët Boigny, Côte d'Ivoire \\ ${ }^{2}$ UFR Agriculture, Ressources Halieutiques et Agro-industrie, Université de San Pedro, Côte d'Ivoire \\ Email: *konesol2003@yahoo.fr
}

How to cite this paper: Jacques, A.A., Soleymane, K., Sékou, D. and El-Hadji Sawaliho, B. (2022) Comparison of Molecular Properties (Stabilities, Reactivity and Interaction) of Manzamenones and Two Antimalarial Drugs (Quinine and Artemisinin) Using Mixed Method Calculations (ONIOM) and DFT (B3LYP). Computational Chemistry, 10, $1-18$.

https://doi.org/10.4236/cc.2022.101001

Received: December 19, 2021

Accepted: January 24, 2022

Published: January 27, 2022

Copyright $\odot 2022$ by author(s) and Scientific Research Publishing Inc. This work is licensed under the Creative Commons Attribution International License (CC BY 4.0).

http://creativecommons.org/licenses/by/4.0/

\begin{abstract}
Malaria is a real public health problem. It's one of the pathologies that mobilize the scientific community. Resistance to existing treatments is the basis for the search for new treatments. Some molecules such as Manzamenones have shown important antimalarial properties. These molecules belong to the family of atypical fatty acid derivatives. This work presents the relative stabilities, some reactivity properties and the privileged sites of interaction by hydrogen bond of fourteen Manzamenones and two antimalarial drugs: quinine and Artemisinin. These analyses were performed using quantum chemical calculations. We employed the two-layer ONIOM calculation method; namely ONIOM (B3LYP/6-311++G (d, p): AM1) for the fourteen Manzamenones. The geometries of the two antimalarials are calculated at B3LYP/6-311++G $(d, p)$. The electrostatic potential (ESP) calculation of all molecules is done at the B3LYP/6-31++G (d, p) level. The formation processes of the molecules are discussed from the thermodynamic quantities we have calculated. The relative stabilities, the energies of the frontier orbitals, the energy gaps, the dipole moment, etc., are evaluated and discussed. The electrostatic potential at the molecular surface has been used to identify the sites favorable to the formation of hydrogen bonds.
\end{abstract}

\section{Keywords}

Manzamenone, Antimalarial Drug, Quantum Chemistry, Reactivity, Electrostatic Potential 


\section{Introduction}

Malaria is a parasitic disease caused by the infection of erythrocytes by a protozoan haematophagous Plasmodium species. It is transmitted to humans through the bite of an infected female Anopheles mosquito [1]. The vulnerable population is pregnant women and young children. In 2015, 214 million infections were reported, including approximately 438,000 deaths with $90 \%$ of deaths coming from the African region [2] [3] [4]. Malaria is caused by five parasites of the species Plasmodium, but the majority of deaths are caused by Plasmodium falciparum and Plasmodium vivax [2] [5] [6] [7]. Drugs such as Quinine, Quinoline, Mefloquine and Artemisinin have been effective in the treatment of this disease. Since about 25 years, the parasite has been developing resistance to the main classes of drugs. Quinine is the drug usually used in severe cases. Cases of resistance to this molecule have been recorded [8] [9] [10]. Manzamenones from marine sources derived from sponges may increasingly be extracted and used in the diversification of drug sources for the treatment of malaria [11].

Manzamenones are atypical fatty acid derivatives, of bicyclic or spiro form, attached or not to a ring with the presence of long hydrocarbon chains substituted on the bicyclic. In the genus Plakortis, they are present in different derivatives such as Manzamenones J, $\mathrm{K}$ and a trimer, Manzamenone $\mathrm{O}$ [12] [13]. These molecules have different biological activities. It is the case of Manzamenone $\mathrm{O}$ that presents an antibacterial activity on the strain Micrococcus luteus, and antifungal on the strains Aspergillus niger and trichophyton mentagrophytes. The research work already carried out on these molecules has focused on the biological analysis, synthesis and structural characterization of these molecules [11] [14]. For the diversity of their biological activities, especially the antimalarial activity, our work focuses on the analysis of the molecular properties and reactivity of the fourteen (14) Manzamenones listed in the literature. These data will be compared to those of two antimalarials: quinine and artemisinin. To achieve this, optimization calculations of the geometries of the molecules are performed in the gas phase. We have calculated the total energies, the thermodynamic quantities of formation and deduced the relative stabilities. The reactivity parameters are calculated. These include $\mathrm{E}_{\text {Hомо }}$ and $\mathrm{E}_{\mathrm{LUMO}}$ energies to apply molecular frontier orbital theory, chemical softness and hardness, chemical potential and electrophilia index. For all Manzamenones, Quinine and Artemisinin, we performed an analysis of the electrostatic potential of the molecular surface. This analysis will allow us to detect the sites of intermolecular interactions for each molecule studied.

The optimization calculations of the Manzamenone geometries are done at the ONIOM level (B3LYP/6-311++G(d,p): AM1). The optimization of the structures of Quinine and Artemisinin is done at the level B3LYP/6-311++G(d, p). As for the calculations of the electrostatic potential, they are done at the level B3LYP/6-31++G(d, p). 


\section{Molecules Studied and Calculation Methods}

\subsection{Studied Molecules: Manzamenones, Quinine and Artemisinin}

Fourteen (14) Manzamenones have been listed in the literature. These molecules are heterocyclic atypical fatty acids. According to the similarities or differences presented by these different structures, groupings were made. Three sets or groups have been constituted. The first set consists of seven Manzamenones whose reference codes (Refcodes) are A, B, C, D, E, F and H. These seven Manzamenones are six- and five-membered bicyclic compounds. Their basic skeleton, bicyclo [4, $3,0]$ nonane, is given in Figure 1.

Manzamenones A and B differ only in the configuration of carbon $\mathrm{C}_{5}$. They are thus said to be epimers. Manzamenones C, F and D are obtained from Manzamenone A by replacing in position 5 the carboxylic acid function respectively by ethyl ester, n-butyl ester and amide functions. As for Manzamenones $\mathrm{E}$ and $\mathrm{H}$, their structures are obtained from that of Manzamenone A by replacing the hydroxyl group of the carboxylic acid function in position 5 with $\mathrm{N}$-valinyl (E) and 4-ethylamine phenol $(\mathrm{H})$.

Three Manzamenones of refcodes L, M and N compose a second group. They have the same basic skeleton as the Manzamenones of the first group. The hydroxyl group in position 1 distinguishes these molecules. The structure of Manzamenone L contains a methyl ester function at positions 2, 5 and 8. Manzamenone $\mathrm{M}$ is obtained by replacing the methyl ester function in position 5 by a carboxylic acid function. Concerning manzamenone $\mathrm{N}$, its structure does not contain a hydroxyl group in position 1 on the bicyclo. It contains on the one hand the three esters functions like Manzamenone $\mathrm{L}$ and on the other hand two double bonds between C2-C3 and C1-C6. These two double bonds are conjugated with the carbonyl group.

Four Manzamenones of refcodes G, J, K and O form the third set. These molecules do not have a common skeleton structure.

The structures of the fourteen Manzamenones are shown in Figure 2, and those of Quinine and Artemisinin are in Figure 3.

\subsection{Calculation Methods}

\subsubsection{ONIOM Method}

The ONIOM method, developed by Morokuma et al. [15] [16] [17], has often been used successfully on large molecules [18] [19] [20] [21]. This method consists

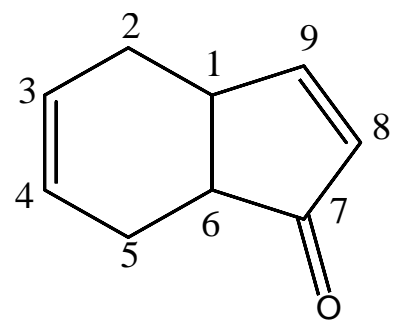

Figure 1. Basic structure and numbering of Manzamenones A, B, C, D, E, F and H. 


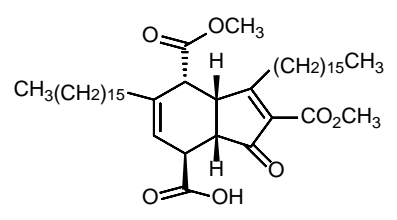

A

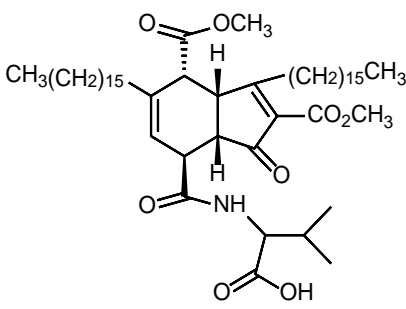

E

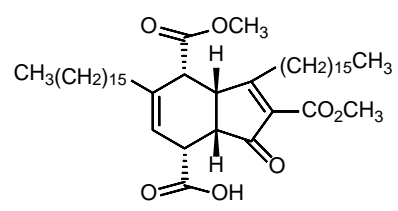

B

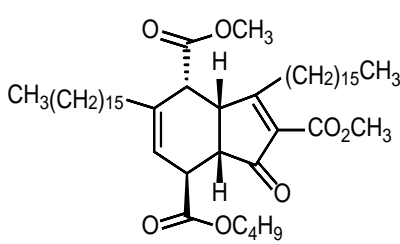

F

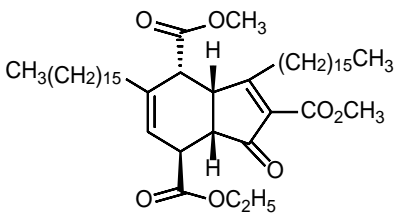

C

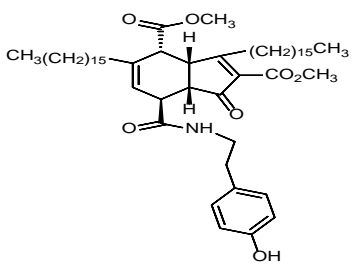

$\mathrm{H}$

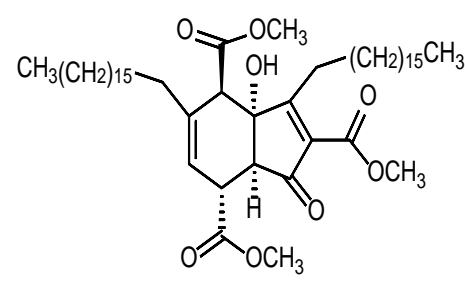

L

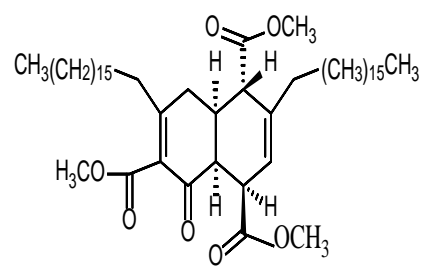

G

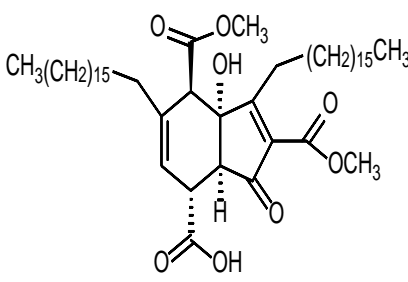

M

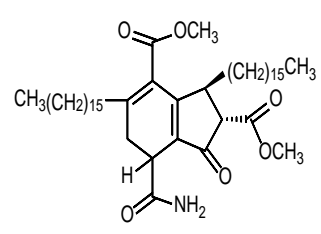

J

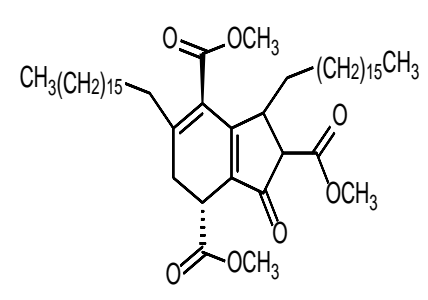

$\mathrm{N}$

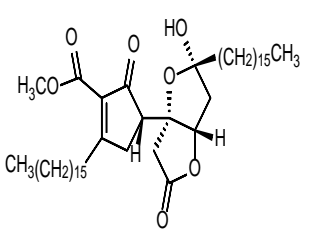

K

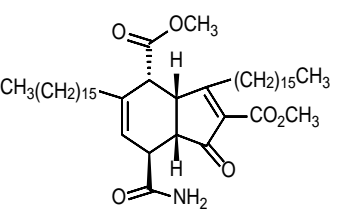

D

Figure 2. Structures of the 14 Manzamenones designated by their refcodes according to the sets (groups) formed.<smiles>C=CC1CN2CCC(C2)[C@H]1C(O)c1ccnc2ccc(OC)cc12</smiles>

Quinine

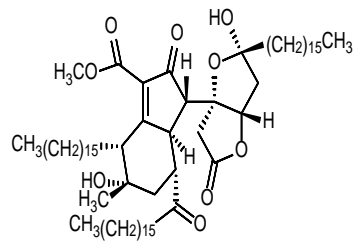

O

Figure 3. Structures of Quinine and Artemisinin.

in splitting the studied system into several layers. Each of these layers is treated at a different level of calculation. The model system will also be processed at the low level. The final goal is to extrapolate the energy of the real system to the high level. The total energy of the real system, determined by extrapolation from three independent calculations, will be calculated according to Equation (1).

$$
E_{\text {real }}^{\text {high }}=E_{\text {real }}^{\text {low }}+E_{\text {model }}^{\text {high }}-E_{\text {model }}^{\text {low }}
$$

The ONIOM2 partitioning adopted for Manzamenones for the application of this calculation method is shown in Figure 4. 


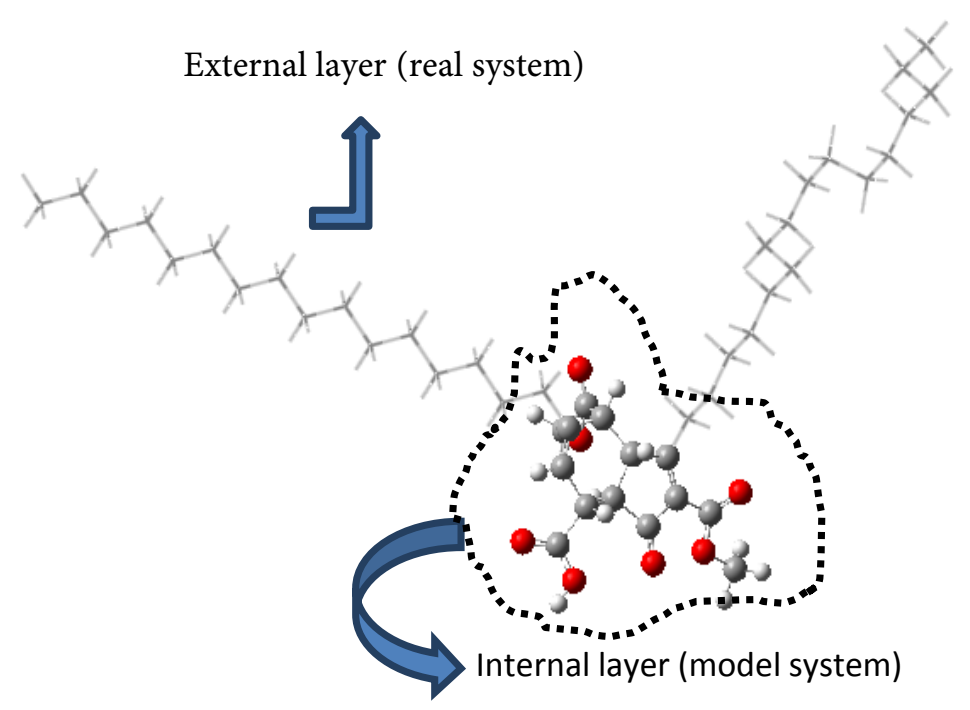

Figure 4. Model of a two-layer partitioning of the structure of a Manzamenone.

\subsubsection{Validation of the Calculations of the Mixed Method ONIOM}

The compatibility of the levels of theory chosen to formulate the mixed method necessarily involves the calculation of the error. The ONIOM method gives very good approximations when the error is zero or very small. Such a result means that the level of theory chosen for the real system combines perfectly with that chosen for the model system. However, for a non-zero error value, these levels are not compatible. The ONIOM method cannot therefore produce good approximations. In our ONIOM calculations (B3LYP/6-311++G(d, p): AM1), the low level is AM1 and B3LYP/6-311++G(d,p) is the high level. The structures of the real and model systems (Figure 4 ) in Manzamenones are optimized with these levels of theory respectively. The error estimate $\left(E_{r r}\right)$ in the ONIOM method is defined as the energy difference between the real and model systems. It is calculated from the relation (2).

$$
E_{r r}=E^{\mathrm{ONIOM} 2}-E_{\text {real }}^{\text {high }}
$$

Taking into account the expression of $E^{\mathrm{ONIOM} 2}$ (1) the error can be given as:

$$
\begin{aligned}
E_{r r} & =\left(E_{\text {model }}^{\text {high }}+E_{\text {real }}^{\text {low }}-E_{\text {model }}^{\text {low }}\right)-E_{\text {real }}^{\text {high }} \\
\text { Finally: } & E_{r r}=\left(E_{\text {real }}^{\text {low }}-E_{\text {model }}^{\text {low }}\right)-\left(E_{\text {real }}^{\text {high }}-E_{\text {model }}^{\text {high }}\right)
\end{aligned}
$$

The evaluation of the error in the ONIOM 2 method $\left(E_{r r}\right)$, requires either the calculation of the energies of the model system at the low and high levels $\left(E_{\text {model }}^{\text {low }}, E_{\text {model }}^{\text {High }}\right)$ and the energies of the real system at the low and high levels $\left(E_{\text {real }}^{\text {low }}, E_{\text {real }}^{\text {high }}\right)$, or the calculation of the energies $E^{\text {ONIOM } 2}$ and $E_{\text {real }}^{\text {high }}$.

\subsubsection{Levels of Theory of Calculation}

The calculations are performed with the Gaussian 09 software [22]. For the calculations with the mixed method (ONIOM), we used for the low level of theory the semi-empirical method AM1 [23]. For the high level of theory, the density functional theory (DFT) [24] is used. Previous theoretical works on the calcula- 
tion of molecular properties have shown that hybrid functionals such as B3LYP and others, associated with an extended basis of functions lead to values in good agreement with experimental results [25]. The level of theory retained for the optimization and frequency calculations of the Manzamenone structures is B3LYP/6-311++G(d, p): AM1. The structures of Quinine and Artemisinin are calculated at the level is $\mathrm{B} 3 \mathrm{LYP} / 6-311++\mathrm{G}(\mathrm{d}, \mathrm{p})$. The electrostatic potential of the molecular surface of each of the molecules is calculated at the B3LYP/6-31++ $\mathrm{G}(\mathrm{d}, \mathrm{p})$ level. The energetic, thermodynamic, stability parameters and the electrostatic interaction potential (ESP) were determined from these different calculations.

\subsection{Reactivity Parameters}

The chemical potential $\mu_{\text {pot }}$ is the tendency of the electronic cloud to escape from the molecule. It is an overall property of the molecular system. The chemical potential is also equal to the opposite of the electronegativity $\chi$ as defined by Paulin and Mulliken [26]-[32].

$$
\mu_{\mathrm{pot}}=\left(\frac{\partial E}{\partial N}\right)_{V(r)}=-\chi
$$

It can be expressed by the ionization potential $P I$ and the electronic affinity $A E$.

$$
\mu_{\mathrm{pot}}=-\frac{P I+A E}{2}=-\chi
$$

The first derivative of the chemical potential regarding the electron number $N$ leads to the chemical hardness $\eta$ and are inverse the softness $S$ [33] [34] [35].

$$
\eta=\left(\frac{\partial \mu}{\partial N}\right)_{V(r)}=\left(\frac{\partial^{2} E}{\partial N^{2}}\right)_{V(r)}=\frac{1}{\sigma}
$$

According to the theory of acids and bases, developed by Pearson [28], these quantities can be expressed in terms of ionization potential $(P I)$ and electronic affinity $(A E)$.

$$
\eta=\frac{1}{S}=\frac{P I-A E}{2}
$$

The ionization potential $(P I)$ and electronic affinity $(A E)$ are easily obtained in the Koopmans approximation [36] by:

$$
P I=-\varepsilon_{\text {Hомо }} \text { et } A E=-\varepsilon_{\text {LUMO }}
$$

$\mathcal{E}_{\text {HOMO }}$ and $\varepsilon_{\text {LUMO }}$ are the energies of the highest occupied orbital (HOMO) and the lowest vacant orbital (LUMO), respectively. This is the theory of frontier molecular orbitals [37].

The electrophilia index $\omega[38]$ is a descriptor developed to evaluate the ability of a molecule to enhance electron transfer. It is calculated from the following relationship.

$$
\omega=\frac{\mu^{2}}{2 \eta}
$$




\subsection{Molecular Electrostatic Potential}

The intermolecular interactions have a mainly an electrostatic nature [39]. This quantity is very often used to reveal molecular interaction sites [40] [41] [42]. The electrostatic potential (ESP) is defined by Equation (11) below.

$$
V(r)=\sum_{A}^{\text {Noyaux }} \frac{Z_{A}}{\left|R_{A}-r\right|}-\int \frac{\rho\left(r^{\prime}\right) \mathrm{d} r^{\prime}}{\left|r^{\prime}-r\right|}
$$

where $Z_{A}$ is the charge of nuclei $A, R_{A}-r$ and $r^{\prime}-r$ are respectively the proton-nuclei and proton-electron distances, and $\rho\left(r^{\prime}\right)$ is the electronic density.

In this work, we selected the electrostatic potential extrema calculated at the molecular surface, $V s_{\max }$ and $V s_{\min }$, to identify and analyze the respective HB donor and acceptor sites in Manzamenones. Indeed, several previous studies carried out on molecules of biological interest (nicotine and derivatives, progesterone) [43] [44] [45] have shown the interest of $V s_{\min }$ for the study of HB acceptor sites.

\section{Results and Discussion}

\subsection{Compatibility of Theory Levels in ONIOM 2}

The ONIOM 2 method, formulated as indicated, was applied to the fourteen Manzamenones in Figure 2. The different energies of the real and model systems as well as the extrapolated energy $E^{\mathrm{ONIOM} 2}$ were estimated. The error resulting from the compatibility of the calculation levels was also evaluated. The results are shown in Table 1.

Table 1. Values of model and real system energies calculated at high (B3LYP/6-311++ $\mathrm{G}(\mathrm{d}, \mathrm{p})$ ) and low (AM1) levels, extrapolated energy and error from the ONIOM calculation on Manzamenones. Energies are in atomic units (a.u).

\begin{tabular}{ccccccc}
\hline Manzamenones & $E_{\text {Model }}^{\text {high }}$ & $E_{\text {Model }}^{\text {low }}$ & $E_{\text {real }}^{\text {low }}$ & $E_{\text {real }}^{\text {high }}$ & $E^{\text {ONIOM 2 }}$ & $E_{r r}$ \\
\hline A & -1068.6054 & -0.2091 & -0.3671 & -1068.7634 & -1068.7633 & 0.0001 \\
B & -1068.6054 & -0.2091 & -0.3671 & -1068.7634 & -1068.7633 & 0.0001 \\
C & -1147.1472 & -0.1035 & -0.1943 & -1147.2380 & -1147.2380 & 0.0000 \\
D & -1048.7187 & -0.1155 & -0.6369 & -1048.4857 & -1048.4858 & 0.0001 \\
E & -1394.8377 & -0.4473 & -0.7949 & -1395.1853 & -1395.1853 & 0.0000 \\
F & -1265.4073 & -0.3979 & -0.7308 & -1265.7402 & -1265.7402 & 0.0000 \\
G & -1147.0794 & -0.0349 & -0.2284 & -1147.2729 & -1147.2729 & 0.0000 \\
H & -1433.9104 & -0.3238 & -0.6699 & -1434.2565 & -1434.2565 & 0.0000 \\
J & -1048.9075 & -0.2894 & -0.6225 & -1049.2406 & -1049.2407 & -0.0001 \\
K & -1030.6777 & -0.4033 & -0.7469 & -1031.0213 & -1031.0214 & -0.0001 \\
L & -1183.3285 & -0.4091 & -0.7565 & -1183.6759 & -1183.6759 & 0.0000 \\
M & -1144.0296 & -0.4285 & -0.7671 & -1144.3682 & -1144.3683 & -0.0001 \\
N & -1108.1192 & -0.3810 & -0.7232 & -1108.4614 & -1108.4614 & 0.0000 \\
O & -1414.6280 & -0.4367 & -0.9411 & -1415.1324 & -1415.1325 & -0.0001 \\
\hline
\end{tabular}


The analysis of the values for the fourteen Manzamenones shows that the error is zero or very close to zero. This means that the two levels are compatible and should lead to results with good approximations. The ONIOM calculations (B3LYP/6-311++G(d, p): AM1) can be used to study the structures of Manzamenones.

\subsection{Thermodynamic Formation Quantities}

The variations of enthalpies of formation, entropies of formation and free enthalpies of formation are calculated for the fourteen Manzamenones, Quinine and Artemisinin. These values are obtained at the B3LYP/6-311++G(d, p) level of theory in the gas phase at $273.15 \mathrm{~K}$. They are reported in Table 2. Examples of optimized structures of Manzamenones (A, E, L and J), Quinine and Artemisinin are shown in Figure 5.

The values of the enthalpies of formation $\Delta_{f} H$ and free enthalpies of formation $\Delta_{f} G$ for each of the molecules studied are all negative. The formation processes of these different molecules are therefore spontaneous and exothermic. The results show that the entropy (disorder) increases during the formation processes of the molecules.

Analysis of the enthalpies of formation $\Delta_{f} H$ show that the Artemisnin formation process is the least energetic, $-602,898.25 \mathrm{kcal} \cdot \mathrm{mol}^{-1}$. The heats of formation

Table 2. Thermodynamic quantities of formation of Manzamenones; calculated (in $\mathrm{kcal} / \mathrm{mol}$ ) at the ONIOM level (B3LYP/6-311++G(d, p): AM1). These quantities are calculated at the level B3LYP/6-311++G(d,p) for Quinine and Artemisinin.

\begin{tabular}{cccc}
\hline Molecules & $\Delta_{f} H$ & $\Delta_{f} G$ & $\Delta_{f} S$ \\
\hline Artemisinin & $-602,898.25$ & $-602,937.04$ & 38.79 \\
Quinine & $-650,320.69$ & $-650,365.44$ & 44.76 \\
A & $-670,130.44$ & $-670,250.89$ & 120.45 \\
B & $-670,130.44$ & $-670,250.89$ & 120.45 \\
C & $-719,441.03$ & $-719,566.70$ & 125.67 \\
D & $-657,649.81$ & $-657,771.40$ & 121.58 \\
E & $-874,643.31$ & $-874,777.63$ & 134.31 \\
F & $-793,431.31$ & $-793,560.93$ & 129.61 \\
G & $-719,439.99$ & $-719,564.30$ & 124.31 \\
H & $-899,152.30$ & $-899,285.41$ & 133.10 \\
J & $-657,637.67$ & $-657,755.38$ & 117.70 \\
K & $-646,217.05$ & $-646,334.88$ & 117.83 \\
L & $-741,986.20$ & $-742,110.40$ & 124.20 \\
M & $-717,337.32$ & $-717,458.49$ & 121.16 \\
N & $-694,789.68$ & $-694,913.57$ & 123.89 \\
O & $-886,866.71$ & $-887,028.62$ & 161.91 \\
\hline & & & \\
\hline
\end{tabular}




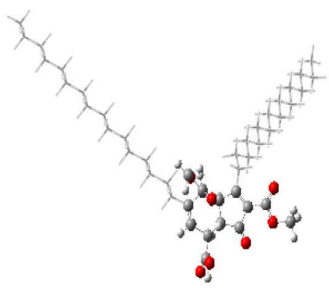

A

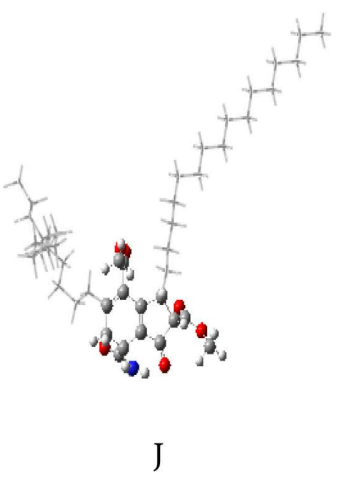

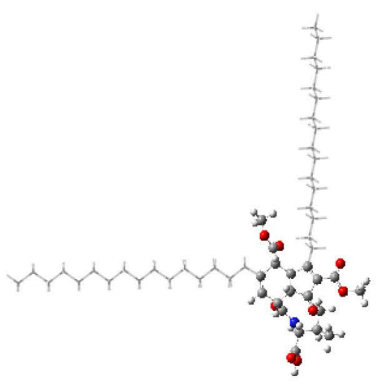

$\mathrm{E}$

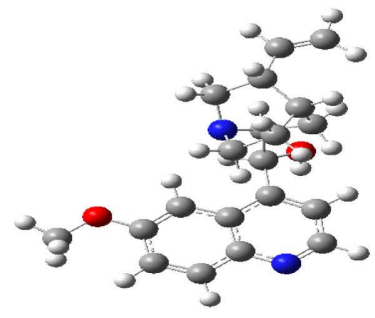

Quinine

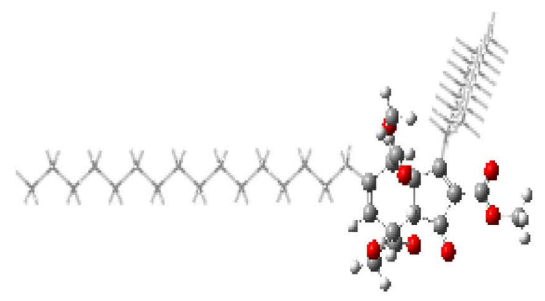

$\mathrm{L}$

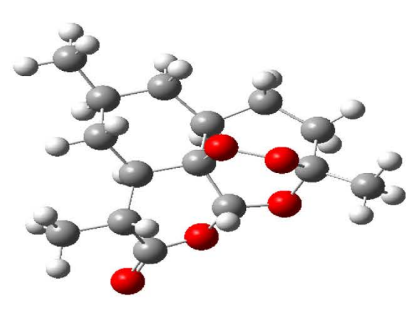

Artemisinin

Figure 5. Optimized structures of some Manzamenones (A, E, L, J), Quinine and Artemisinin.

of Quinine, Manzamenones $\mathrm{K}$, J and D are quite close in values. They are respectively $-650,320.69 \mathrm{kcal} \cdot \mathrm{mol}^{-1},-646,217.05 \mathrm{kcal} \cdot \mathrm{mol}^{-1},-657,637.67 \mathrm{kcal} \cdot \mathrm{mol}^{-1}$ and $-657,649.81 \mathrm{kcal} \cdot \mathrm{mol}^{-1}$. According to the study conditions of this work, each of the presented molecules is obtained according to a spontaneous and exothermic process. The heats of formation of Manzamenones are between $-646,217.05 \mathrm{kcal} \cdot \mathrm{mol}^{-1}$ and $-899,152.30 \mathrm{kcal} \cdot \mathrm{mol}^{-1}$. Their formation reactions are globally more energetic than those leading to the formation of Artemisinin and Quinine whose heats of formation are respectively $-602,898.25 \mathrm{kcal} \cdot \mathrm{mol}^{-1}$ and $-650,320.69 \mathrm{kcal} \cdot \mathrm{mol}^{-1}$.

\subsection{Global Reactivity Indexes}

The reactivity parameters considered in this list of compounds are all global descriptors of molecular structures. They are HOMO $\left(E_{\text {Hомо }}\right)$, LUMO $\left(E_{\mathrm{LUMO}}\right)$, chemical potential $\left(\mu_{\text {pot }}\right)$, electrophilia index $(\omega)$, chemical hardness $(\eta)$, chemical softness $(S)$, frontier orbital energy gap $(\Delta E)$, and dipole moment $\left(\mu_{D}\right)$. The energy values of the frontier orbitals and those of some global descriptors are shown in Table 3.

The total energies of Quinine, Artemisinin and the 14 Manzamenones are between $-603,134.92 \mathrm{kcal} \cdot \mathrm{mol}^{-1}$ and $-900,039.00 \mathrm{kcal} \cdot \mathrm{mol}^{-1}$. They are therefore very stable molecules. Except for Artemisinin, the least stable of the described molecules is the Manzamenone $\mathrm{K}$ with a total energy of $-646,996.83 \mathrm{kcal} \cdot \mathrm{mol}^{-1}$. Therefore, it was used as a reference to establish relative stability $\left(\Delta E_{\mathrm{tot}}\right)$. According to our calculations, Quinine is more stable than this Manzamenone by 
Table 3. Total energy $\left(E_{\mathrm{tot}}\right)$ and relative stability $\left(\Delta E_{\mathrm{tot}}\right)$ in $\mathrm{kcal} \mathrm{mol}^{-1}$, frontier orbital energies $\left(E_{\mathrm{HOMO}}\right.$ and $\left.E_{\mathrm{LUMO}}\right)$, energy gap $(\Delta \mathrm{E})$, chemical potential $\left(\mu_{\text {Pot }}\right)$, chemical hardness $(\eta)$ and electrophilia $(\omega)$ in $\mathrm{eV}$, dipole moment $\left(\mu_{D}\right)$ in $\mathrm{D}$, chemical softness $(S)$ in $\mathrm{eV}^{-1}$.

\begin{tabular}{|c|c|c|c|c|c|c|c|c|c|c|}
\hline Molecules & $E_{\text {tot }}$ & $\Delta E_{\text {tot }}$ & $E_{\text {номо }}$ & $E_{\mathrm{LUMO}}$ & $\Delta E$ & $\mu_{\text {Pot }}$ & $\eta$ & $S$ & $\omega$ & $\mu_{D}$ \\
\hline Artemisinin & $-603,134.92$ & $43,861.91$ & -7.11 & -1.17 & 5.94 & -4.14 & 2.97 & 0.34 & 2.89 & 4.16 \\
\hline Quinine & $-650,590.45$ & -3593.62 & -5.88 & -1.77 & 4.12 & -3.83 & 2.06 & 0.49 & 3.55 & 2.19 \\
\hline A & $-670,914.89$ & $-23,918.06$ & -10.31 & -0.98 & 9.33 & -5.65 & 4.66 & 0.21 & 3.42 & 5.84 \\
\hline B & $-670,914.89$ & $-23,918.06$ & -10.31 & -0.98 & 9.33 & -5.65 & 4.66 & 0.21 & 3.42 & 5.84 \\
\hline $\mathrm{C}$ & $-720,262.50$ & $-73,265.67$ & -10.24 & -1.03 & 9.21 & -5.64 & 4.61 & 0.22 & 3.45 & 3.82 \\
\hline $\mathrm{D}$ & $-658,442.22$ & $-11,445.39$ & -9.83 & -1.32 & 8.52 & -5.57 & 4.26 & 0.24 & 3.65 & 2.96 \\
\hline $\mathrm{E}$ & $-875,520.64$ & $-228,523.81$ & -10.22 & -0.80 & 9.42 & -5.51 & 4.71 & 0.21 & 3.23 & 2.38 \\
\hline $\mathrm{F}$ & $-794,289.96$ & $-147,293.13$ & -8.83 & -0.90 & 7.93 & -4.87 & 3.96 & 0.25 & 2.99 & 5.48 \\
\hline G & $-720,261.98$ & $-73,265.15$ & -9.94 & -0.90 & 9.04 & -5.42 & 4.52 & 0.22 & 3.25 & 6.38 \\
\hline $\mathrm{H}$ & $-900,039.00$ & $-253,042.17$ & -9.27 & -1.28 & 7.99 & -5.27 & 3.99 & 0.25 & 3.48 & 2.40 \\
\hline $\mathrm{J}$ & $-658,430.01$ & $-11,433.18$ & -9.92 & -0.99 & 8.93 & -5.46 & 4.47 & 0.22 & 3.33 & 8.49 \\
\hline $\mathrm{K}$ & $-646,996.83$ & 0.00 & -10.87 & -0.81 & 10.06 & -5.84 & 5.03 & 0.20 & 3.39 & 5.57 \\
\hline $\mathrm{L}$ & $-742,792.15$ & $-95,795.32$ & -8.88 & -1.04 & 7.84 & -4.96 & 3.92 & 0.26 & 3.14 & 5.77 \\
\hline $\mathbf{M}$ & $-718,125.41$ & $-71,128.58$ & -10.06 & -1.02 & 9.05 & -5.54 & 4.52 & 0.22 & 3.39 & 4.74 \\
\hline $\mathbf{N}$ & $-695,592.75$ & $-48,595.92$ & -9.79 & -1.43 & 8.36 & -5.61 & 4.18 & 0.24 & 3.76 & 2.77 \\
\hline $\mathrm{O}$ & $-888,038.08$ & $-241,041.25$ & -10.36 & -0.62 & 9.74 & -5.49 & 4.87 & 0.21 & 3.09 & 4.79 \\
\hline
\end{tabular}

about $3594 \mathrm{kcal} \cdot \mathrm{mol}^{-1}$. As for Artemisinin, it is less stable by about 43862 $\mathrm{kcal} \cdot \mathrm{mol}^{-1}$. Compared to the reference, four Manzamenones are distinguished by a very high stability. These are Manzamenones $\mathrm{H}, \mathrm{O}, \mathrm{E}$ and $\mathrm{F}$; they are more stable by $253,042.17 \mathrm{kcal} \cdot \mathrm{mol}^{-1}, 241,041.25 \mathrm{kcal} \cdot \mathrm{mol}^{-1}, 228,523.81 \mathrm{kcal} \cdot \mathrm{mol}^{-1}$ and $147,293.13 \mathrm{kcal} \cdot \mathrm{mol}^{-1}$ respectively.

The optimal structures of Manzamenones have HOMO energies between -8 $\mathrm{eV}$ and $-11 \mathrm{eV}$. These energies do not vary according to the order of stability of these molecules. Artemisinin and Quinine have their highest HOMO; $-7.11 \mathrm{eV}$ and $-5.88 \mathrm{eV}$ respectively. However, Quinine has the lowest LUMO $(-1.77 \mathrm{eV})$ of all the molecules in Table 3. Artemisinin has its LUMO $(-1.17 \mathrm{eV})$ located in the energy range of the Manzamenone LUMO $(-0.80 \mathrm{eV}$ to $-1.43 \mathrm{eV})$. With the lowest energy gap $(4.12 \mathrm{eV})$, Quinine is more reactive than all other molecules, it is followed by Artemisinin ( $5.94 \mathrm{eV}$ ). The Manzamenones described have larger energy gaps that vary little between $7.84 \mathrm{eV}$ and $10.06 \mathrm{eV}$. Manzamenones B and $\mathrm{E}$ have potent enzymatic activities [46]; $\mathrm{M}$ and $\mathrm{N}$ have antimicrobial activities [47]; A, F, and L have considerable anti-oxidant activities [48]; and $\mathrm{A}$ and $\mathrm{O}$ have anticancer activities [49]. These results indicate that the biological activities of these Manzamenones do not depend on the energy gap value.

The dipole moment is the descriptor resulting from the distance between the barycenters of the positive and negative charges. It depends, for a molecule, on 
its geometry. This explains the remarkable differences between the values of the dipole moment of Manzamenones. All the Manzamenones studied in this work have their dipole moments between $2.38 \mathrm{D}$ and $8.49 \mathrm{D}$.

They are all more polar than Quinine (2.19 D). The dipole moment of Artemisinin is $4.16 \mathrm{D}$. Being a parameter that reflects intermolecular interactions [50], these results show that all these molecules would have stronger intermolecular interactions than Quinine. Some Manzamenones (J, G, A, B, L, K, F, O and $\mathrm{M})$ with higher dipole moments than Artemisinin would lead to stronger interamolecular interactions than this molecule. For the other Manzamenones (C, $\mathrm{D}, \mathrm{E}, \mathrm{H}$ and $\mathrm{N}$ ), their molecular interactions would be weaker.

\subsection{Determination of Molecular Interaction Sites}

For the analysis of the electrostatic potential at the molecular surface, a numbering of the heteroatoms of all carbon atoms carrying hydrogen(s) is always adopted. When a carbon carries two or three hydrogens, an average value of the potential is calculated. The numbering adopted for the $V s_{\min }$ and $V s_{\max }$ assignments of Artemisinin and Quinine are shown in following Figure 6.

The different numbering of the atoms in the Manzamenone structures are made according to their similarities or differences. Figure 7 shows these numberings.

Some examples of maps of the electrostatic potential calculated at the B3LYP/ $6-31++G(d, p)$ level are shown in Figure 8.

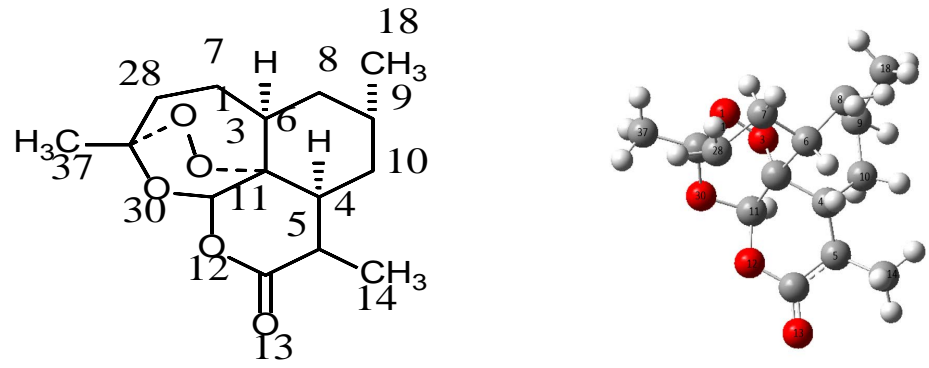

Artemisinin
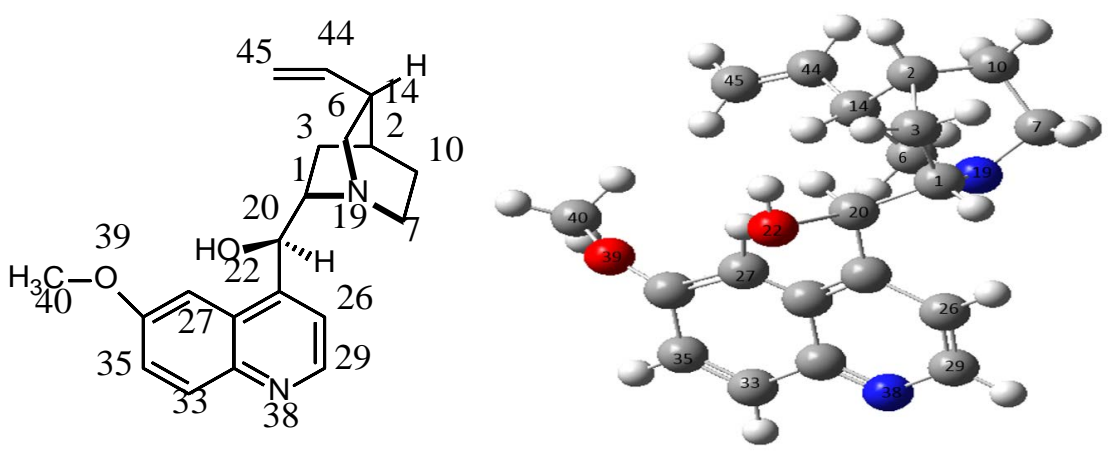

Quinine

Figure 6. 2D and 3D structures showing the atomic numbering of Artemisinin and Quinine for the analysis of their ESP. 

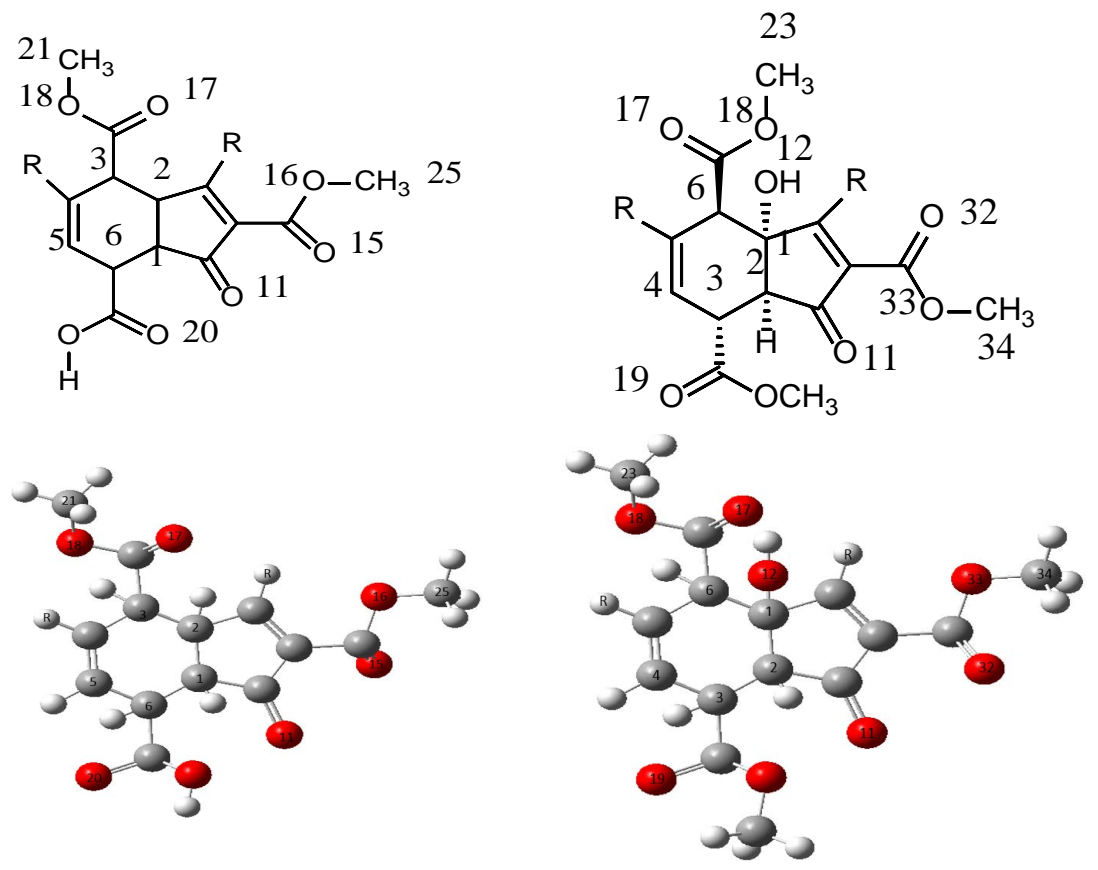

A, B, C, D, E, F et H

L, M et $\mathrm{N}$
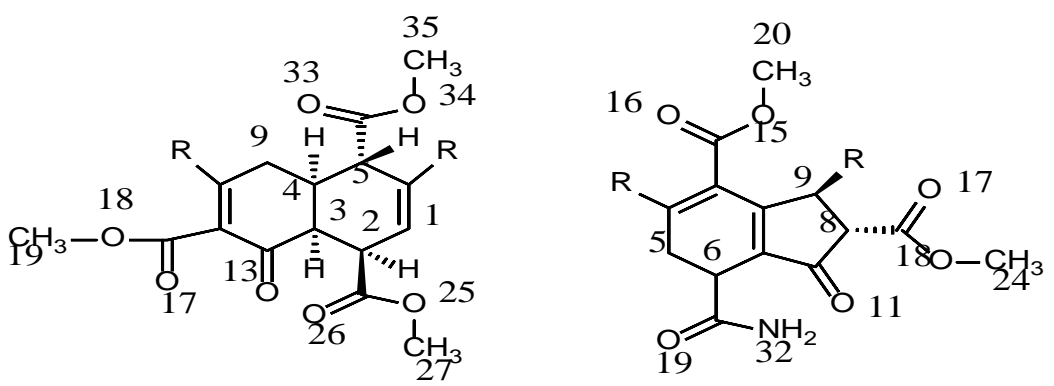

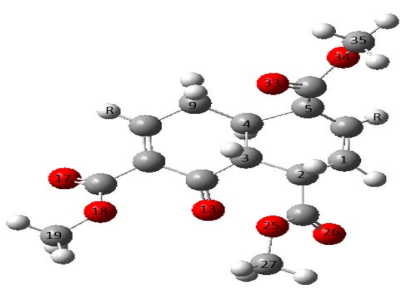

G

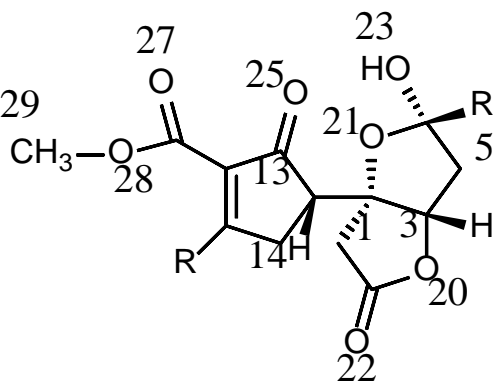

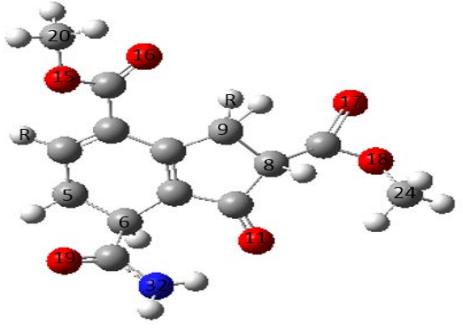

J

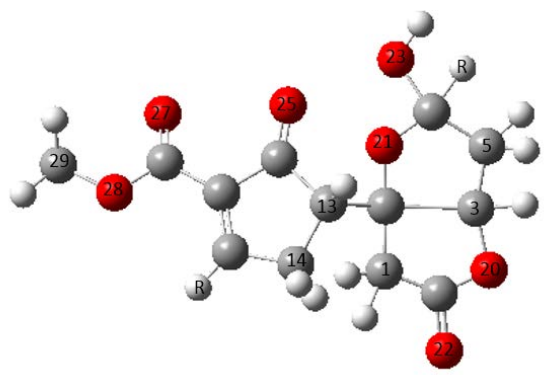

K

Figure 7. 2D and 3D structures of Manzamenones showing atomic numbering for ESP analysis. 


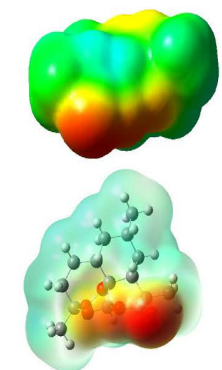

Artemisinin

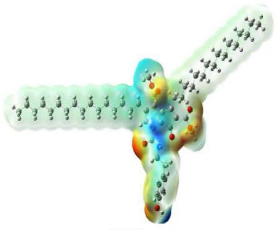

$\mathrm{H}$

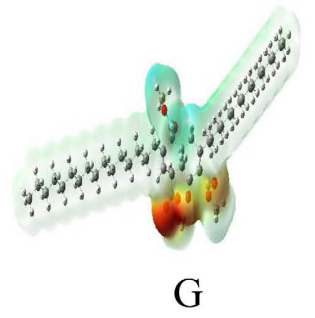

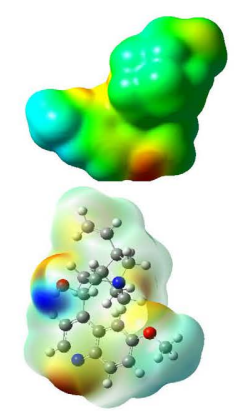

Quinine

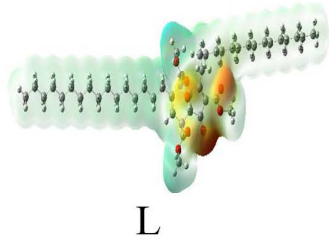

$\mathrm{L}$

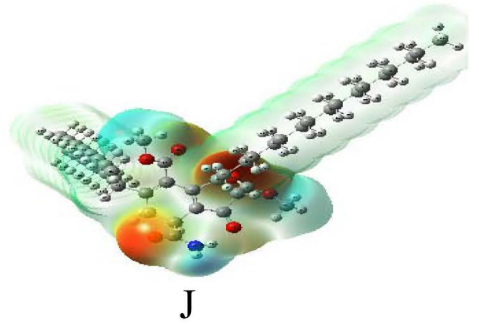

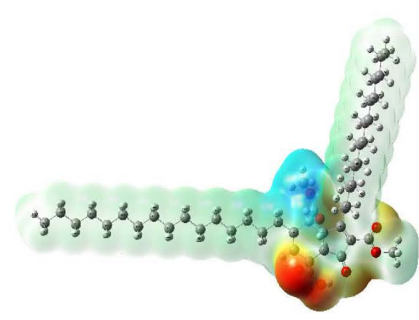

A

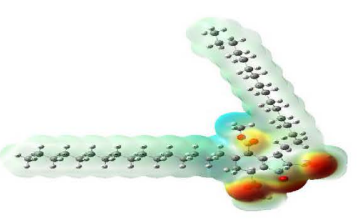

$\mathrm{N}$

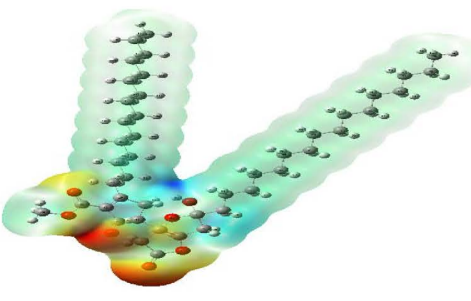

$\mathrm{K}$

Figure 8. Electrostic potential maps of Quinine, Artemisinin and Manzamenones A, H, L, N, G, J and K.

The electrostatic potential maps of Artemisinin, Quinine, and thirteen Manzamenones were explored. Sites with $V s_{\min }$ or $V s_{\max }$ values were identified. These sites are reported in Table 4 . They constitute, for $V s_{\max }$, the electron-rich regions thus hydrogen bond acceptors. The sites of $V s_{\max }$ are poor in electrons; thus donors of hydrogen bonds.

The results in Table 4 show that the Manzamenones classified in the first two sets (A, B, C, D, E, H, L, M and N) have three (3) preferred acceptor sites. The other molecules each have two (2) sites. The molecules with the lowest $V s$ min values are the Manzamenones F, D, C, and L. For these Manzamenones, the acceptor power of said sites decreases in the following order: $\mathrm{L}>\mathrm{F}>\mathrm{D}$ and $\mathrm{C}$.

However, among these molecules, Artemisinin has the strongest $\mathrm{O}_{13} \mathrm{LH}$ acceptor site. All other (oxygen) acceptor sites of the studied molecules (Artemisinin, Quinine and Manzamenones) have little different acceptor powers.

The donor sites attached to the hydrogens of the $\mathrm{OH}$ and $\mathrm{NH}$ groups are the strongest. This is the case in Quinine and in the Manzamenones A(B), D, E, H, $\mathrm{L}, \mathrm{M}$, J and $\mathrm{K}$. The $\mathrm{OH}$ donor site always has the strongest donor capacity. Manzamenone $\mathrm{M}$ contains two $\mathrm{OH}$ donors. This molecule could establish strong intermolecular interactions from these $\mathrm{OH}$ groups. The Manzamenones $\mathrm{E}$ and $\mathrm{H}$ each have an $\mathrm{OH}$ donor and an $\mathrm{NH}$ donor. 
Table 4. Privileged acceptor and donor site(s) from the electrostatic interaction potential calculation.

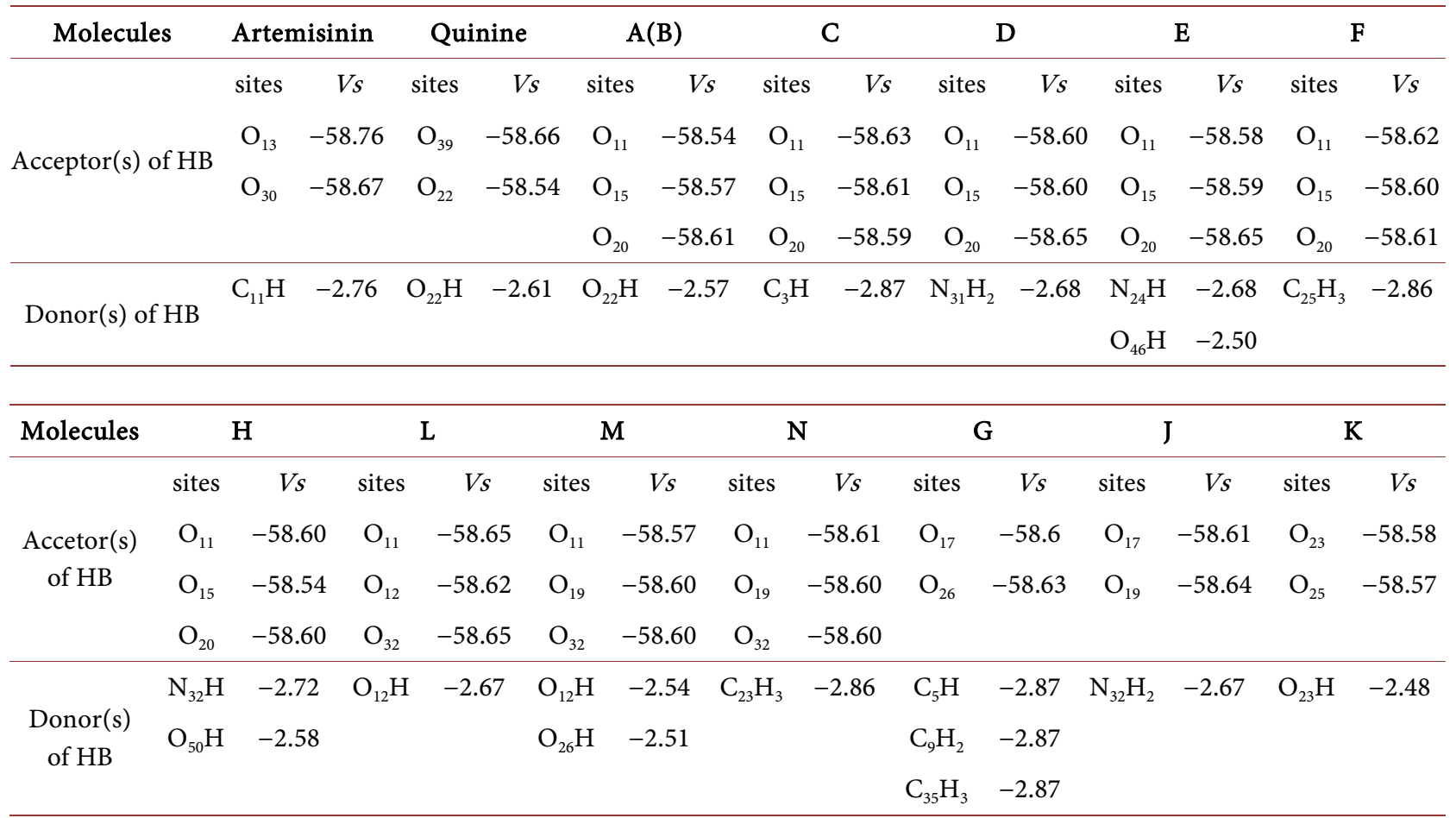

\section{Conclusions}

This work presents the results of the comparative study of the stability, some reactivity properties and the electrostatic potential of the molecular surface of fourteen (14) Manzamenones with two antimalarials: Quinine and Artemisinin. The two-layer ONIOM method was used for the analysis of the stability and reactivity properties of Manzamenones. Thus, the model system and the two antimalarials are studied at the B3LYP/6-311++G(d, p) level. The real system in Manzamenones is described using the semi-empirical AM1 method. We have shown that the two levels of theory used are compatible with ONIOM calculations.

Our calculations revealed that the reactions of formation of Manzamenones are spontaneous and exothermic processes. The heats are between $-646,217.05$ $\mathrm{kcal} \cdot \mathrm{mol}^{-1}$ and $-899,152.30 \mathrm{kcal} \cdot \mathrm{mol}^{-1}$. These reactions are more energetic than those leading to the formation of Artemisinin and Quinine whose heats of formation are respectively $-602,898.25 \mathrm{kcal} \cdot \mathrm{mol}^{-1}$ and $-650,320.69 \mathrm{kcal} \cdot \mathrm{mol}^{-1}$.

Quinine, Artemisinin and the fourteen Manzamenones have their total energies between $-603,134.92 \mathrm{kcal} \cdot \mathrm{mol}^{-1}$ and $-900,039.00 \mathrm{kcal} \cdot \mathrm{mol}^{-1}$. These molecules are globally stable. Artemisinin is the least stable molecule of all. Quinine is more stable than Manzamenone K. Four Manzamenones E, F, H and O showed very high stability. The two antimalarials have lower energy gaps than the fourteen Manzamenones ranging from $7.84 \mathrm{eV}$ to $10.06 \mathrm{eV}$. All Manzamenones studied in this work are more polar than Quinine $(2.19 \mathrm{D})$. The dipole moment of Artemisinin is estimated to be $4.16 \mathrm{D}$. For Manzamenones, it varies between 2.38 
$\mathrm{D}$ and $8.49 \mathrm{D}$.

The analysis of the electrostatic potential at the molecular surface (ESP) of all the molecules allowed us to identify the sites $V s_{\min }$, rich in electrons thus acceptors of hydrogen bonds and the sites of $V s_{\max }$ are poor in electrons; thus donors of hydrogen bonds.

\section{Conflicts of Interest}

The authors declare no conflicts of interest regarding the publication of this paper.

\section{References}

[1] Olumese, P. (2005) Epidemiology and Surveillance: Changing the Global Picture of Malaria-Myth or Reality? Acta Tropica, 95, 265-269.

https://doi.org/10.1016/j.actatropica.2005.06.006

[2] Reddy, P.L., Khan, S.I., Ponnan, P., Tripathi, M. and Rawat, D.S. (2017) Synthesis and Evaluation of 4-Aminoquinoline-Purine Hybrids as Potential Antiplasmodial Agents. European Journal of Medicinal Chemistry, 126, 675-686. https://doi.org/10.1016/j.ejmech.2016.11.057

[3] Maurya, S.S., Khan, S.I., Bahuguna, A., Kumar, D., Rawat, D.S. (2017) Synthesis, Antimalarial Activity, Heme Binding and Docking Studies of N-Substituted 4-Aminoquinoline-Pyrimidine Molecular Hybrids. European Journal of Medicinal Chemistry, 129, 175-185. https://doi.org/10.1016/j.ejmech.2017.02.024

[4] Singh, A., Gut, J., Rosenthal, P.J. and Kumar, V. (2017) 4-Aminoquinoline-Ferrocenyl-Chalcone Conjugates: Synthesis and Anti-Plasmodial Evaluation. European Journal of Medicinal Chemistry, 125, 269-277. https://doi.org/10.1016/j.ejmech.2016.09.044

[5] Jones, R.A., Panda, S.S. and Hall, C.D. (2015) Quinine Conjugates and Quinine Analogues as Potential Antimalarial Agents. European Journal of Medicinal Chemistry, 97, 335-355. https://doi.org/10.1016/j.ejmech.2015.02.002

[6] Murugan, K., Raichurkar, A.V., Rahman, F., Khan, N. and Iyer, P.S. (2015) Synthesis and in Vitro Evaluation of Novel 8-Aminoquinoline-Pyrazolopyrimidine Hybrids as Potent Antimalarial Agents. Bioorganic \& Medicinal Chemistry Letters, 25, 1100-1103. https://doi.org/10.1016/j.bmcl.2015.01.003

[7] White, N.J., Pukrittayakamee, S., Hien, T.T., Faiz, M.A., Mokuolu, O.A. and Dondorp, A.M. (2014) Malaria. The Lancet, 383, 723-735.

https://doi.org/10.1016/S0140-6736(13)60024-0

[8] White, N.J., Nosten, F., Looareesuwan, S. and Olliaro, P. (1999) Averting a Malaria Disaster. The Lancet, 353, 1965-1967.

https://doi.org/10.1016/S0140-6736(98)07367-X

[9] Demar, M. and Carme, B. (2004) Plasmodium falciparum in Vivo Resistance to Quinine: Description of Tow RIII Responses in French Guinea. American Journal of Tropical Medicine and Hygiene, 70, 125-127. https://doi.org/10.4269/ajtmh.2004.70.125

[10] Turschner, S. and Efferth, T. (2009) Drug Resistance in Plasmodium: Natural Products in the Fight against Malaria. Mini-Reviews in Medicinal Chemistry, 9, 206-214. https://doi.org/10.2174/138955709787316074

[11] Norris, M.D. and Perkins, M.V. (2016) Structural Diversity and Chemical Synthesis 
of Peroxide and Peroxide-Derived Polyketide Metabolites from Marine Sponges. Natural Product Reports, 33, 861-880. https://doi.org/10.1039/C5NP00142K

[12] Takeuehi, S., Kikuehi, T., Tsukamoto, S., Ishibashi, M. and Kobayashi, J. (1995) Three New Oxylipins Related to 3,6 Dioxo-4-Docosenoic Acid from Okinawan Marine Sponges Plakortis spp. Tetrahedron, 51, 5979-5986.

https://doi.org/10.1016/0040-4020(95)00256-8

[13] Tanaka, N., Asai, M., Takahashi-Nakaguchi, A., Gonoi, T., Formont, J. and Kobayashi, J. (2013) Manzamenone O, New Trimeric Fatty Acid Derivative from a Marine Sponge Plakortis sp. Organic Letters, 15, 2518-2521.

https://doi.org/10.1021/ol4009975

[14] Al-Busafi, S. and Whitehead, R.C. (2000) Predispositon in Synthesis: Efficient Routes to $( \pm)$-Untenone A and ( \pm )-Manzamenones A, C and F. Tetrahedron Letters, 41, 3467-3470. https://doi.org/10.1016/S0040-4039(00)00399-3

[15] Maldanis, R.J., Wood, J.S., Chandrasekaran, A., Rauusch, M.D. and Chien, J.C.W. (2002) The Formation and Polymerization Behavior of Ni(II)-Diimine Complexes Using Various Aluminum Activators. Journal of Organometallic Chemistry, 645, 158-167. https://doi.org/10.1016/S0022-328X(01)01340-7

[16] Morokuma, K. (2002) New Challenges in Quantum Chemistry: Quests for Accurate Calculations Forlarge Molecular Systems. Philosophical Transactions of the Royal Society A: Mathematical, Physical and Engineering Sciences, 360, 1149-1164. https://doi.org/10.1098/rsta.2002.0993

[17] Dapprich, S., Komáromi, I., Byun, K.S., Morokuma, K. and Frisch, M.J. (1999) A New ONIOM Implementation in Gaussian98. Part I. The Calculation of Energies, Gradients, Vibrational Frequencies and Electric Field Derivatives. Journal of Molecular Structure: THEOCHEM, 461, 1-21. https://doi.org/10.1016/S0166-1280(98)00475-8

[18] Vreven, T. and Morokuma, K. (2000) On the Application of the IMOMO (Integrated Molecular Orbital+Molecular Orbital) Method. Journal of Computational Chemistry, 21, 1419-1432. https://doi.org/10.1002/1096-987X(200012)21:16\%3C1419::AID-JCC1\%3E3.0.CO;2-C

[19] Zheng, F. and Zhan, C.G. (2008) Rational Design of an Enzyme Mutant for AntiCocaine Therapeutics. Journal of Computer-Aided Molecular Design, 22, 661-671. https://doi.org/10.1007/s10822-007-9144-9

[20] Ruangpornvisuti, V. (2004) Recognition of Carboxylate and Dicarboxylates by Azophenol-Thiourea Derivatives: A Theoretical Host-Guest Investigation. Journal of Molecular Structure: THEOCHEM, 686, 47-55.

https://doi.org/10.1016/j.theochem.2004.08.007

[21] Samanta, P.N. and Das, K.K. (2016) Prediction of Binding Modes and Affinities of 4-Substituted-2,3,5,6-Tetrafluorobenzenesulfonamide Inhibitors to the Carbonic Anhydrasereceptorby Docking and ONIOM Calculations. Journal of Molecular Graphics and Modelling, 63, 38-48. https://doi.org/10.1016/j.jmgm.2015.11.010

[22] Frisch, M.J., Trucks, G.W., Schlegel, H.B., Scuseria, G.E., Robb, M.A., Cheeseman, J.R., Scalmani, G., Barone, V., Mennucci, B., Petersson, G.A., Nakatsuji, H., Caricato, M., Li, X., Hratchian, H.P., Izmaylov, A.F., Bloino, J., Zheng, G., Sonnenberg, J.L., Hada, M., Ehara, M., Toyota, K., Fukuda, R., Hasegawa, J., Ishida, M., Nakajima, T., Honda, Y., Kitao, O., Nakai, H., Vreven, T., Montgomery, J.A., Peralta, J.E., Ogliaro, F., Bearpark, M., Heyd, J.J., Brothers, E., Kudin, K.N., Staroverov, V.N., Kobayashi, R., Normand, J., Raghavachari, K., Rendell, A., Burant, J.C., Iyengar, S.S., Tomasi, J., Cossi, M., Rega, N., Millam, J.M., Klene, M., Knox, J.E., Cross, J.B., Bakken, V., Adamo, C., Jaramillo, J., Gomperts, R., Stratmann, R.E., Yazyev, O., 
Austin, A.J., Cammi, R., Pomelli, C., Ochterski, J.W., Martin, R.L., Morokuma, K., Zakrzewski, V.G., Voth, G.A., Salvador, P., Dannenberg, J.J., Dapprich, S., Daniels, A.D., Farkas, O., Foresman, J.B., Ortiz, J.V., Cioslowski, J. and Fox, D.J. (2009) Gaussian, Inc., Wallingford, CT.

[23] Jakalian, A., Jack, D.B. and Bayly, C.I. (2002) Fast, Efficient Generation of High-Quality Atomic Charges. AM1-BCC Model: II. Parameterization and Validation. Journal of Computational Chemistry, 23, 1623-1641. https://doi.org/10.1002/jcc.10128

[24] Hohenberg, P. and Kohn, W. (1964) Inhomogeneous Electron Gas. Physical Review, 136, B864. https://doi.org/10.1103/PhysRev.136.B864

[25] Koch, W. and Holthausen, M.C.A (1999) A Chemist's Guide to Density Functional Theory. 2nd Edition, Wiley-VCH, Weinheim.

[26] Geerlings, P., De Proft, F. and Langenaeker, W. (2003) Conceptual Density Functional Theory. Chemical Reviews, 103, 1793-1874.

https://doi.org/10.1021/cr990029p

[27] Chermette, H. (1999) Chemical Reactivity Indexes in Density Functional Theory. Journal of Computational Chemistry, 20, 129-154.

https://doi.org/10.1002/(SICI)1096-987X(19990115)20:1\%3C129::AID-JCC13\%3E3. $\underline{0 . \mathrm{CO} ; 2-\mathrm{A}}$

[28] Pearson, R.G. (1963) Hard and Soft Acids and Bases. Journal of the American Chemical Society, 85, 3533-3539. https://doi.org/10.1021/ja00905a001

[29] Caro, C.A., Zagal, J.H., Bedioui, F., Adamo, C. and Cardenas-Jiron, G.I. (2004) Solvent Effect on Density Functional Reactivity Indexes Applied to Substituted Nickel Phthalocyanines. The Journal of Physical Chemistry A, 108, 6045-6051. https://doi.org/10.1021/jp049530y

[30] Cardenas-Jiron, G.I., Gutierrez-Oliva, S., Melin, J. and Toro-Labbe, A. (1997) Relations between Potential Energy, Electronic Potential and Hardness Profiles. The Journal of Physical Chemistry A, 101, 4621-4627. https://doi.org/10.1021/jp9638705

[31] Parr, R.G., Donnelly, R.A., Levy, M. and Palke, W.E. (1978) Electronegativity: The Density Functional Viewpoint. The Journal of Chemical Physics, 68, 3801-3807.

[32] Mulliken, R.S. (1934) A New Electroaffinity Scale, Together with Data on Valence States and on Valence Ionization Potentials and Electron Affinities. The Journal of Chemical Physics, 2, 782-793.

[33] Sanderson, R.T. (1951) An Interpretation of Bond Lengths and a Classification of Bond. Science, 114, 670-672. https://doi.org/10.1126/science.114.2973.670

[34] Parr, R.G. and Pearson, R.G. (1983) Absolute Hardness: Companion Parameter to Absolute Electronegativity. Journal of the American Chemical Society, 105, 7512-7516. https://doi.org/10.1021/ja00364a005

[35] Yang, W. and Parr, R.G. (1985) Hardness, Softness and the Fukui Function in the Electronic Theory of Metals and Catalysis. Proceedings of the National Academy of Sciences of the United States of America, 82, 6723-6726. https://doi.org/10.1073/pnas.82.20.6723

[36] Koopmans, T. (1934) Uber die zuordnung von wellenfunk-tionen und eigenwerten zu den einzelnen elektronen eines atoms. Physica, 1, 104-113. https://doi.org/10.1016/S0031-8914(34)90011-2

[37] Fukui, K., Yonesawa, T. and Shingu, H. (1952) A Molecular Orbital Theory of Reactivity in Aromatic Hydrocarbons. The Journal of Chemical Physics, 20, 722-725.

[38] Parr, R.G., Szentpaly, L.V. and Liu, S. (1999) Electrophilicity Index. Journal of the American Chemical Society, 121, 1922-1924. https://doi.org/10.1021/ja983494x 
[39] Hunter, C.A. (2004) Quantifying Intermolecular Interactions: Guidelines for the Molecular Recognition Toolbox. Angewandte Chemie International Edition, 43, 5310-5324. https://doi.org/10.1002/anie.200301739

[40] Hagelin, H., Murray, J.S., Brinck, T., Berthelot, M. and Politzer, P. (1995) Family-Independent Relationships between Computed Molecular Surface Quantities and Solute Hydrogen Bond Acidity/Basicity and Solute-Induced Methanol O-H Infrared Frequency Shifts. Canadian Journal of Chemistry, 73, 483-488.

https://doi.org/10.1139/v95-063

[41] Brinck, T. (1998) The Use of the Electrostatic Potential for Analysis and Prediction of Intermolecular Interactions. Theoretical and Computational Chemistry, 5, 51-93. https://doi.org/10.1016/S1380-7323(98)80005-8

[42] Kenny, P.W. (1994) Prediction of Hydrogen Bond Basicity from Computed Molecular Electrostatic Properties: Implications for Comparative Molecular Field Analysis. Journal of the Chemical Society, Perkin Transactions, 2, 199-202.

https://doi.org/10.1039/p29940000199

[43] Arnaud, V., Berthelot, M., Evain, M., Graton, J. and Le Questel, J.Y. (2007) Hydrogen-Bond Interactions of Nicotine and Acetylcholine Salts: A Combined Crystallographic, Spectroscopic, Thermodynamic and Theoretical Study. Chemistry- $\mathrm{A} \mathrm{Eu}$ ropean Journal, 13, 1499-1510. https://doi.org/10.1002/chem.200600808

[44] Graton, J., Berthelot, M., Gal, J.F., Laurence, C., Lebreton, J., Le Questel, J.Y., Maria, P.C. and Robins, R. (2003) The Nicotinic Pharmacophore: Thermodynamics of the Hydrogen-Bonding Complexation of Nicotine, Nornicotine, and Models. The Journal of Organic Chemistry, 68, 8208-8221. https://doi.org/10.1021/jo035018h

[45] Le Questel, J.Y., Boquet, G., Berthelot, M. and Laurence, C. (2000) Hydrogen Bonding of Progesterone: a Combined Theoretical, Spectroscopic, Thermodynamic, and Crystallographic Database Study. The Journal of Physical Chemistry B, 104, 1181611823. https://doi.org/10.1021/jp002213g

[46] Wakuda, Y., Kubota, T., Shima, H., Okada, T., Mitsuhashi, S., Aoki, N., Kikuchi, K. and Kobayashi, J. (2006) Manzamenones Inhibit T-Cell Protein Tyrosine Phosphatase. Marine Drugs, 4, 9-14. https://doi.org/10.3390/md401009

[47] Kubota, T., Ishiguro, Y., Takahashi-Nakaguchi, A., Fromont, J., Gonoib, T. and Kobayashi, J. (2013) Manzamenones L-N, New Dimeric Fatty-Acid Derivatives from an Okinawan Marine Sponge Plakortis sp. Bioorganic \& Medicinal Chemistry Letters, 23, 244-247. https://doi.org/10.1016/j.bmcl.2012.10.109

[48] Cho, M.L., Lee, Y.J., Lee, J.S., Shin, H.J. and Lee, H.S. (2020) Antioxidant Properties of the Manzamenones from the Tropical Marine Sponge Plakortis sp. Natural Product Communications, 15. https://doi.org/10.1177/1934578X19896694

[49] Kobayashi, J. (2016) Search for New Bioactive Marine Natural Products and Application to Drug Development. Chemical and Pharmaceutical Bulletin, 64, 1079-1083.

[50] Xavier, S., Periandy, S. and Ramalingam, S. (2015) NBO, Conformational, NLO, HOMO-LUMO, NMR and Electronic Spectral Study on 1-Phenyl-1-Propanol by Quantum Computational Methods. Spectrochimica Acta Part A: Molecular and Biomolecular Spectroscopy, 137, 306-320. https://doi.org/10.1016/j.saa.2014.08.039 